J. A., a little girl, three years of age, residing at 94, Clipstone-streel, Fitzroysqunre, became a patient of mine in November, 1837 ; she was a healthy-looking robust child, with whom one could find no fault, except that she was not so strong upon her legs as she might be, while the abdomen was tense and tumid; her head, spine, and limbs were well developed, and free from sign of rickets. I learnt that the child had had several attacks such as I now witnessed; by one person she was supposed to suffer from disease of the brain, by others from mesenteric disease, and many thought worms were the cause of mischief, in which latter opinion I concurred. When I first saw her I found that there was much fever, hot and dry skin, sleep disturbed by frequent moanings, grinding of teeth, \&c., eyes but partially closed; she referred the pain to the head and belly; to the latter the hand was frequently applied with the words " pain mama." After a few days' treatment with calomel and scammony, and the acetate of anmonia mixture, the bowels having passed a grood deal of viscid slime of different colours, the fit went off, leaving the tongue, which was before dry and much coated with a brown fur, clean. Though the knotted mucus seemed to form such a nidus for worms, none could be detected; however, the bowels had regained their tone, the belly became much softer and smaller, and the patient was thought well.

These attacks continued to recur at about the interval of a month, for several times, with nearly the same treatment, excepting that latterly $I$ gave the mercury and chalk with rhubarb and cinnamon for a more continued time. On the 6th of April I wa's requested to attend quickly, and found that, the child having complained of much "pricking," the powder had been given more frequently, and in consequence a quantity of bloody lymph-like matter had been evacuated, and with it a living leech; relief soon followed, and since that time the little patient has thrived remarkably, and been free from molestation.

It is worthy of notice that for some hours up to the time this unexpected visitor appeared the pricking was incessant about the rectum. It is what $I$ should call a horse leech, of a dark brown colour, without spots, belly clay colour; its size is that of sn ordinary leech; the mouth does not appear triangular as that of the hirudo medicinalis, but sharp like that of the Jumbricus teres; it lived a week, during which time it swam about in the undulating manner which leeches do. I still have it in my possession.

I made particular inquiries as to whether any water had been added to the vessel, and was assured by the mother and servant that it was perfectly clean and dry previously, and no one had been near it but the child; that immediately afterwards they perceired the "thing" to extricate itself from thr gelatinous matter, and climb up the side in the vessel.

I find that the child, with an elder brother, had often been in the habit of getting to the water-butt, each assisting the other to dring from the $\operatorname{tap} ; I$ have no doubt but the leech, perhaps when small, was swallowed in this manner, and had been the cause of considerable irritation, producing sympa. thetic disturbance of the brain.

I recollect two cases being recorded, I think, in Thr Lancer, where leeches lised in the human stomach; in one the man was supposed to die from rupture of a vessel and a leech was found in the stomach with a large quantity of bloor ; in the other case, a large leech was coughed up durigg violent paroxysm, and the man lived.

At my request the water has been closely inspected when drawn, and a leech has been found in every respect like that referred to, but somewhat less, and not knotted, which is the case in the former one.

\section{POISONING WITH OXIDE OF ARSENIC.}

To the Editor of THE LANCET.

SIR:-On Friday, the 21st of September, an inquest was held before Mr. Brown, the Coroner of Nottingham, on the body of Thomas Adcock, who died at 20 'clock in the morning, from the effects of oxide of arsenic, taken (so far as can be ascertained from the evidence) about a quarter before 8 o'clock on Thursday evening. As it was not then known that he had died from poison. and as no testimony could be obtained as to the cause of his death, $I$ was requested to make an examination of the body, and give evidence. As I consider the appearane: interesting, both as regards the more inme. diate effects of the poison upon the stomad and the remote effects upon the brain lungs, heart, \&c., I have much pleasure ir transmitting an account of them to you fo insertion in THE LANCET. It wonld hart been still more interesting if $I$ could har given you an account of the symptoms dut ing life, but as I did not see him until afte death, I am unable to do so.

The hypertrophy of the heart, and th softening of the thalami and corpora striata were, no doubt, previously existing states I am, Sir, your obedient servant, JOSEPH ThOMSON, Surgeon to the Nottingham Dispensis!

Head. The sinuses of the brain were fil of black blood, and there was slight serot effusion into the cavity of the arachnor and lateral ventricles, and a little also unde the arachnoid, and at the upper part of th posterior lobes of the cerebrum, near to th 
longitudinal fissures; this was more fibrinous in its character and stationary, presenting an opaque appearance. The pia mater was so much congested that, when carefully separated from the brain and spread out, it looked like a red membranous sheet. In some places the ressels had given way so as to form spots of extravasation; but these were not numerous, and were situated at the inferior surface of the posterior lobes of the cerebrum. On making the usual sections in the brain numerous large dark bloody points were perceived; the difference in colour between the cortical and medullary portions of the brain was very marked; the thalami and corpora striata were rather softer than natural; the venx Galeni were distended with blood, as were also the arteries forming the circle of Willis ; the cerebellum, on being incised, showed many bloody points; the plexus choroides was not so vascular as might have been expected from the state of the pia mater.

Chest.-The lungs were extremely gorged with blood, particularly at the posterior thick border; the right adhered throughout its whole extent, except at the anterior border, to the parietes of the chest, by an old adhesion, in which, towards the posterior border of the ling, there was found a calcareous concretion as large as a small nut; on separating the lung from the ribs, where the adhesion existed, it was accidentally torn, when much dark blood, of a gelatinous consistence, escaped from its textures. I mention this to show the degree of pulmo. nary engorgement, which was quite as great on the left side where there was not any adhesion ; the heart was hypertrophied, particularly the left side, which was full of dark, scarcely coagulated blood, as was also the aorta; the pulmonic cavities of the heart, and the venæe cavæ, were also filled with dark blood and the auriculo-ventricular opening on this side was considerably dilated.

Abdomen.-The stomach was much distended, and contained about two pints of a brownish-red fluid, with large portions of riscid mucus, entangling a quantity of white powder; some portions of mucus, containing a similar powder, adhered to the mucous membrane; when rubbed between the fingers it had a gritty feel; the stomach was large and thick, which latter alteration seemed chiefly owing to the injected condition of the mucous membrane, for its vascularity was so great as to give it an uniform red appearance, except at the cardiac extremity, opposite the great curvature, where there was a portion of a bluish slaty colour, and a little to the right of this a good many small dark spots of extravasation, seated chiefly on the rugæ, giving the stomach at this part a mottled appearance ; there were not any coagula of blood, nor any solid food contained in the stomach; the mucous mem- brane was rather more easily separated than usual; the mucous membrane of the duodenum was very vascular, and contained a reddish fluid. No other observation was made worthy of notice, $w$ ith this exception, that the veins of the mesentery were turgid with dark blood, and likewise those proceeding from the abdominal viscera generally. I think the quantity of oxide of arsenic taken could not have been less than half an ounce, judging from the quantity I collected and allowing for loss.

\section{CARBONATE OF SUDA.}

\section{To the Editor of TuE Lancet.}

SIr :-In Magendie's third lecture on the blood he has advanced an opinion that large doses of carbonate of soda have the power of producing pneumonia, " by liquefy ing the blood," and causing infiltration of the lungs, and, as the grounds of his belief in this respect, he adduces only a single case. Now, as the weight which attaches to everything advanced on such high authority might influence many in the employment of so common and useful a remedy, I will just simply state, that $I$ am acquainted with two individuals who have taken, for months past, half a pound of carbonate of soda every week, not only without injury, but with the best possible effects as regards the complaints for which they still continue its use. The names of these persons are Birchley and Summers; the former lives at Castlemorton, in Worcestershire, and is well known as the huntsman of the Ledbury fox hounds. Summers is a brewer, living in the latter place.

Birchley for years laboured under a most severe spasmodic affection of the abdomen, for which he had consulted every one of any note, far and near, without receiving any but the most temporary benefit. The paroxysms were so severe that he has been ohliged, when hunting, to dismount from his horse, and press with the abdomen violently on the earth, to obtain relief, and this has been observed by many spectators. He has also had these attacks in the night.

When I last saw him, he told me that he had completely cured himself by taking these large doses of the carbonate of soda, and that he occasionally had recourse to it to prevent relapse.

Summers's complaint was somewhat similar, and he learnt the use of the remedy from Birchley, and has taken it with the same beneficial results. I remain, Sir, your constant reader,

\section{Congreve Selwyn.}

34, Clarence-square, Pittville, Cheltenham, Oct. 19. 